\title{
El discurso educativo del nacionalcatolicismo y la formación del magisterio español*
}

Teresa González Pérez

\begin{abstract}
Profesora e investigadora de la Universidad de la Laguna (España). Correo electrónico: teregonz@ull.edu. es. La autora es doctora en Historia, Maestra, Licenciada en Historia, Licenciada en Filosofía y Ciencias de la Educación por la Universidad de La Laguna. Entre sus publicaciones recientes tenemos: "Maestros para la democracia. La formación inicial del magisterio en España con la Ley de Ordenación General del Sistema Educativo", Historia da Educação Vol. 22 No. 54 (2018), "La identidad cultural en Canarias y su proyección educativa”, en Teresa González Pérez (coord.), Identidades Culturales y Educación (Valencia/Tirant, 2017) y "Políticas educativas igualitarias en España. La igualdad de género en los estudios de magisterio", Archivos Analíticos de Políticas Educativas Vol. 26 No. 2 (2016). Entre sus temas de interés están Historia de la Educación, Formación del magisterio, Historia regional y Educación de las mujeres.
\end{abstract}

Recibido: 5 de abril de 2017

Aprobado: 13 de marzo de 2018

Modificado: 21 de marzo de 2018

Artículo de investigación científica

DOI: http://dx.doi.org/10.15648/hc.33.2018.5

* $\quad$ Este artículo forma parte del proyecto: "La pedagogía académica y la formación inicial del magisterio durante el franquismo" financiado por el Vicerrectorado de Investigación de la Universidad de La Laguna (España).

Esta publicación está bajo una licencia Creative Commons Reconocimiento-NoComercial 4.0 
El discurso educativo del nacionalcatolicismo y la formación del magisterio español

\title{
Resumen
}

Desde los primeros momentos de la rebelión militar, la ideología del nacionalcatolicismo anuló toda práctica educativa ajena a sus principios, poniendo un cerco a las innovaciones metodológicas y la renovación pedagógica. En este artículo estudiamos la formación inicial del magisterio español durante el franquismo. La capacitación de los aprendices del magisterio se realizó a través de unos planes de estudio diseñados por las autoridades educativas que desde el control ideológico, con una enseñanza sexista y segregada, sentaron las bases de la educación. Alejados de la modernidad pedagógica impusieron el modelo de maestro y maestra ideal y prefijaron los arquetipos de la masculinidad y feminidad. La evolución política y social condujo a la progresiva transformación de estos estudios, una trayectoria que culmina con el rango universitario y la enseñanza mixta.

Palabras clave: Nacionalcatolicismo, magisterio, programas, educación, masculinidad, feminidad.

The educational discourse of National Catholicism and the formation of the Spanish Faculty

\begin{abstract}
From the earliest moments of the military rebellion, the ideology of National Catholicism annulled any educational practice unrelated to its principles, putting a fence to methodological innovations and pedagogical renewals. In this article we study the early formation of the Spanish faculty during the Franco's regime. The training of teachers was carried out through curricula designed by educational authorities, who from an ideological control and with sexist and segregated teaching, set the foundations of education. Away from the pedagogical modernity they imposed the model of the ideal teacher and predetermined the archetypes of masculinity and femininity. The political and social evolution led to the progressive transformation of these studies, a trajectory

84 that culminates into higher education and coeducation.
\end{abstract}

Keywords: National Catholicism, faculty, programs, education, masculinity, femininity. 


\section{O discurso educativo do nacionalcatolicismo e a formação do magisterio espa-} nhol

\section{Resumo}

Desde os primeiros momentos da rebelião militar, a ideologia do nacionalcatolicismo anulou toda prática educativa a margem de seus princípios, pondo um cerco às inovações metodológicas e a renovação pedagógica. Neste artigo estudamos a formação inicial do magisterio espanhol durante o franquismo. A capacitação dos aprendices do magisterio realizou-se através de uns planos de estudo desenhados pelas autoridades educativas que desde o controle ideológico, com um ensino sexista e segregada, sentaram as bases da educação. Afastados da modernidad pedagógica impuseram o modelo de maestro e maestra ideal e prefixaram os arquetipos da masculinidad e feminidad. A evolução política e social conduziu à progressiva transformação destes estudos, uma trajectória que culmina com a faixa universitária e o ensino misto.

Palavras-chave: nacionalcatolicismo, magisterio, programas, educação, masculinidad, feminidad.

\section{Nacionalcatolicismo discours éducatif et la formation d'enseignement de l'es- pagnol}

\section{Resumé}

Dès les premiers moments de la rébellion militaire, l’idéologie de nacionalcatolicismo annulé toute pratique éducative étrangère ses principes, mettre une clôture des innovations méthodologiques et le renouveau pédagogique. Dans cet article, nous étudions la formation initiale des enseignants au cours de la Franco espagnol. La formation des enseignants a été menée apprenants grâce à un programme conçu par les autorités éducatives du contrôle idéologique, avec une éducation séparée sexiste, ils ont jeté les bases de l'éducation. Ils pédagogique loin de la modernité imposées au modèle de l'enseignant idéal et enseignant et se fixent des archétypes de la masculinité et de la féminité. L'évolution politique et sociale a conduit à la transformation progressive de ces études, une trajectoire qui culmine avec le niveau universitaire et la coéducation.

Motsclés: nacionalcatolicismo, la dictature, les enseignants, les programmes, l'éducation, la masculinité, la féminité. 


\section{INTRODUCCIÓN}

Desde los inicios de la guerra civil el franquismo se legitimó a la fuerza, imponiendo un férreo control para perpetuarse en el poder, utilizando el aparato escolar para sustentar la legitimidad del régimen. Se apoyó en la doctrina del nacionalcatolicismo, cuyas connotaciones ideológicas y religiosas propagó entre la población a través de su red de propaganda y especialmente de la educación. Para el nacionalcatolicismo la educación era una herramienta básica para la penetración ideológica, para implantar la cultura política autoritaria y someter a los vencidos ${ }^{1}$. La política educativa del franquismo supuso una ruptura con la etapa anterior, hecho que afectó a los modos de entender la pedagogía. La ideología del nacionalcatolicismo se construyó sobre los valores tradicionales de la sociedad y la Iglesia católica. Recurrió al sistema educativo como instrumento eficaz para transmitir su ideología y sus valores, para inculcar sus pautas morales y sus creencias. El apoyo de la Iglesia resultó crucial para afianzarse en el poder, además de su contribución a la despolitización de la sociedad recibió prerrogativas en la educación y ejerció el control moral, a la vez de la censura y supervisión de los libros.

El carácter confesional católico del régimen dictatorial se hizo patente desde los inicios de la sublevación. Desde el aparato del Estado, con posiciones fundamentalistas, se proclamó la regeneración del catolicismo, se esforzó en modelar las conciencias y en la reconstrucción de los valores tradicionales de la pedagogía. La exclusividad de la enseñanza católica quedó reflejada en las disposiciones oficiales y constituyó el discurso recurrente de las autoridades ${ }^{2}$. De tal modo que, desde los primeros momentos de la rebelión militar, la ideología del nacionalcatolicismo anuló toda prácticaeducativa ajena a sus principios, poniendo un cerco a las innovaciones

1 María Elena Maza Zorrilla, “Las reglas del juego del nacionalcatolicismo”, en Ana Esteban y María Jesús Izquierdo. La revolución educativa en la segunda república y la represión franquista eds. (Valladolid: Ediciones de la Universidad de Valladolid, 2014), 142.

862 Gustavo Alares López, Políticas del pasado en la España franquista (1939-1964). Historia, nacionalismo y dictadura (Madrid: Marcial Pons, 2017); Lino Camprubí Bueno, Los ingenieros de Franco. (Barcelona: Crítica, 2017); Feliciano Montero y Joseba Louzao (eds.), Catolicismo y franquismo en la España de los años cincuenta. Autocríticas y convergencias (Granada: Comares, 2016). 
metodológicas y la renovación pedagógica. Daba prioridad a los contenidos ideológicos frente a los pedagógicos, con la finalidad de potenciar los principios patrióticos, morales y religiosos para modelar las conciencias, mutilando y maquillando el panorama nacional con el objetivo de destruir la memoria republicana.

La legislación se convirtió en un instrumento de poder y control del colectivo. Se dictaron normas específicas para los maestros y maestras tituladas con el Plan Profesional de 1931, así como para el alumnado egresado de dicho plan, al objeto de que cursaran y aprobaran la materia de Religión (Decreto de 10 de febrero de 1940 y Circular del 12 de febrero de 1940). El Ministerio desde el verano de 1937 convocó cursillos de dos semanas de duración para los maestros formados en el plan profesional de 1931, para que ningún maestro ni maestra pudiera ejercer la profesión sin haber superado la formación religiosa. Impuso la pedagogía adecuada al régimen y llevó a cabo una "contrarrevolución pedagógica" cial se realizaron actividades de preparación ideológica (al margen de la realizada con el colectivo profesional). En este sentido, junto a las acciones formativas puestas en marcha por la administración educativa, se destaca el fundamental papel desempeñado por la Iglesia y por la Falange, en la formación político-ideológica del magisterio.

La diversidad de planes de estudio refleja las carencias existentes en la formación inicial. Si bien la trayectoria académica revela distancias entre la ideología y la realidad social, tal como hemos expuesto en trabajos anteriores $^{4}$. La línea descrita se concretó en las construcciones de los saberes, en las formas concretas de organizar el universo de conocimientos, que debían integrar la capacitación inicial del magisterio de acuerdo con los postulados ideológicos del régimen. No obstante, el diseño de diferentes modelos de aprendices de maestros y maestras estaba condicionado por

3 José Ramón López Bausela, La contrarrevolución pedagógica en el franquismo de guerra. El proyecto político de Pedro Sainz Rodríguez (Madrid: Biblioteca Nueva / Ediciones de la Universidad de Cantabria, 2011), 22.

4 Teresa González Pérez, "Formar maestros y maestras para la patria nacional-católica. Los estudios de magisterio en la España franquista (1936-1975)", History of Education \& Children's Literature, XII, 2 (2017): 69-91. 
las circunstancias que envolvían al país. De tal modo que durante el periodo de guerra y de la posguerra se realizaron adaptaciones curriculares del Plan de estudios de 1914 y del Plan Profesional de 1931. También los cursos de formación breve, como el Plan Bachiller y la titulación para los Alférez provisionales, definieron el perfil del magisterio primario de acuerdo a las prioridades del gobierno. Progresivamente se diseñaron y aprobaron cinco planes de estudio que marcaron hitos en la preparación académica. Desde los años difíciles de la posguerra y la autarquía (Plan de 1942, Plan 1945 y Plan 1950) a la tecnocracia (Plan de 1967 y Plan de 1971). Estos planes implementados durante la dictadura reflejan la configuración de dos itinerarios: uno de carácter más ideológico profesional correspondiente al primer franquismo y, otro de carácter más pedagógico que comenzó a percibirse en la década de los años sesenta. Es importante tener en cuenta que los planes de estudio evolucionaron al tiempo que el régimen político. Los gestores educativos los fueron adaptando a las nuevas circunstancias sociales y, con base en ello, actualizando la configuración de una determinada identidad en la preparación del estudiantado. El programa equivalía a un listado de materias curriculares que debían ser enseñadas a la vez que determinaba la instrucción y contenidos de la formación académica.

La formación inicial del magisterio, desde el año 1936 hasta 1975, se caracterizó por el control ideológico y la construcción del modelo magisterial autoritario en sintonía con los valores del nuevo orden. Se rebajó el nivel académico y las exigencias para alcanzar la titulación de magisterio, hasta finales del franquismo cuando se recuperó la categoría universitaria, con el nivel de diplomatura. El modelo formativo sufrió un importante retroceso a nivel curricular y en el plano metodológico. La escasa consideración social de los estudios, y por ende, de la profesión magisterial resultaron negativos. Desde el magisterio se impulsaban los roles de género con una formación diferenciada para maestros y maestras, de tal manera que en la escolaridad reproducirían idénticos modelos entre los niños y las niñas. El objetivo de este trabajo es estudiar el discurso ideológico del nacionalcatolicismo en la formación inicial del magisterio español. Analizamos la trayectoria del perfil profesional a través de los programas de formación inicial, que diseñaron el modelo de maestro y maestra ideal, analizando las bases que sustentaron la construcción de la masculinidad y la feminidad. 
Empleamos la metodología científica diseñada para las investigaciones de carácter histórico educativo. Abordamos los contenidos objeto de estudio con la aportación de fuentes primarias y secundarias, además de las publicaciones realizadas sobre la temática en cuestión. El universo de análisis lo conforman los materiales documentales publicados por el régimen franquista (legislación, textos políticos fundamentales, propaganda, planes de estudio, etc.), las revistas de la época, además, de la revisión de las obras ya editadas.

\section{Algunas cuestiones relativas a la política educativa. La im- PLANTACIÓN DEL MODELO DEL NACIONALCATOLICISMO}

En los años de la contienda (1936-1939) se restringió la vida de las Escuelas de Magisterio. Se limitaron a continuar con la docencia de los cursos iniciados, a las convocatorias de exámenes y a la impartición de cursos intensivos y complementarios, pero no iniciando un plan de estudios. Sobre todo para las alumnas que habían iniciado sus estudios, pues los alumnos fueron movilizados para incorporarlos al ejército. En 1938 se suspendieron las actividades académicas para el alumnado masculino que cursaba estudios. Además para aquellos que no habían cursado las asignaturas de Religión e Historia Sagrada, se dictaron normas específicas para la realización de los exámenes de dichas materias ${ }^{5}$, con la consiguiente obligatoriedad para todos los maestros y maestras del plan profesional ${ }^{6}$, para aprobarlas en las convocatorias de junio o septiembre ${ }^{7}$. La actividad académica en alguno de estos centros se reanudó terminada la guerra ${ }^{8}$, aunque hubo centros que no vieron interrumpida su actividad, al encontrarse en aquellas zonas que quedaron bajo el poder de los nacionales desde los inicios del levantamiento militar. El retraso evidente de su funcionamiento en buena parte de la geografía española, que había sido escenario del conflicto armado, impidió que las Escuelas de Magisterio desempeñaran la tarea para la que habían sido creadas. Desde las editoriales de la revista Escuela

\footnotetext{
5 Órdenes de 7 de noviembre y 11 de diciembre de 1939.

6 Orden de 28 de diciembre de 1939.

7 Colección Legislativa del Ministerio de Educación Nacional, 1940. Circular del Director General de Enseñanza Primaria dirigida a los directores de Escuelas de Magisterio del 12 de febrero de 1940, 31.

$8 \quad$ Orden de 14 de julio de 1939.
} 
Española se solicitaba que se restableciera el funcionamiento pleno y se desempeñaran las tareas asignadas con toda normalidad ${ }^{9}$. El caso es que se demoró la reapertura y entre otras razones, desde las esferas oficiales, se esgrimía que la causa era la entrada en vigor de la Ley de Enseñanza Primaria que se encontraba en proceso de elaboración. No obstante, se articularían medidas transitorias mientras se tramitaba la nueva normati$\mathrm{va}^{10}$. El ministro José Ibáñez Martín anunció que para los años 1942-1943 comenzarían a funcionar por lo menos una escuela por provincia ${ }^{11}$.

El perfil del magisterio se caracterizó por un marcado carácter patriótico y escaso nivel científico, con una importante deficiencia cultural y pedagógica. La formación inicial del magisterio se definía por el control administrativo y de otras instancias sociales para garantizar los principios, la conducta moral y política del régimen. Además de la fuerte presencia de la asignatura de Religión y su Metodología junto a la Formación y Educación Patriótica que constituían los ejes de su preparación. Se impartía una enseñanza sexista y segregada, con un currículo que incluía materias distintas, para un modelo diferenciado entre maestros y maestras, que reflejaban la feminidad y masculinidad de acuerdo a los roles que marcaba la sociedad española del momento.

En esta época, especialmente en las instituciones educativas, se veló por mantener al personal afecto al régimen. Los valores democráticos estaban ausentes, además las bibliotecas de las Escuelas de Magisterio habían sido depuradas como lo fueron sus docentes. Las obras de los grandes pedagogos universales estaban incluidas en la lista de libros prohibidos, debido a la incompatibilidad de los ideales democráticos con los principios del régimen y los objetivos de formar un profesional al servicio de la patria ${ }^{12}$. En los planes de estudio se introdujo una pedagogía decimonónica de corte católica y nacionalista, recogida en las obras de Rufino Blanco, Andrés Manjón y Ramón Ruiz Amado, con el objetivo de formar un tipo de

$9 \quad$ Escuela Española, no 25 (1941): 317.

10 Escuela Española, no 71 (1942): 563.

11 Escuela Española, no 48 (1942): 242.

12 Antonio Viñao Frago "La educación en el franquismo (1936-1975)", Educar em Revista, N. 51, (2014): 26. 
maestro y de maestra tradicional que debía garantizar la transmisión de los valores conservadores, religiosos y patrióticos para perpetuar el orden social basado en la jerarquía, la disciplina y el autoritarismo. De manera que el enfoque pedagógico se subrogaba a la política ideológica y así se refleja en el perfil del magisterio: "Importa la formación científica de los alumnos pero de nada serviría si esta formación científica no está al servicio de estos tres ideales: Dios, España y Nacionalsindicalismo... Nuestra Pedagogía, la que estamos construyendo, la Nacionalsindicalista, ha de ser nuestra, es decir: católica, tradicional y revolucionaria"13. En suma, el objetivo consistía en destruir la memoria republicana y desmantelar los vestigios de la modernidad educativa, dando prioridad a los contenidos ideológicos frente a los pedagógicos, con la finalidad de potenciar los principios patrióticos, morales y religiosos para modelar las conciencias, mutilando y maquillando el panorama nacional. El "nuevo estado" precisaba del magisterio y de las escuelas para sedimentar su proyecto, pues la educación constituía una pieza angular dentro del sistema: "La unidad nacional y el interés de la Patria exigen la cooperación armónica de todos los españoles e incumbe a los Maestros, incorpora al Movimiento nacional, bien preparados para la noble empresa el resurgir de España"14. Así recomendaba el empleo de la pedagogía tradicional encumbrada por Calasanz, Loyola, Manjón, Ponce de León, Vives, entre otros. Las figuras religiosas católicas deudoras de metodologías memorísticas y repetitivas eran los espejos didácticos propuestos, además de aconsejar la lectura de dos obras "admirables y además españolísimas: El Criterio, de Balmes, y El Maestro mirando hacia dentro, de Andrés Manjón... estos libros y aquellos métodos y doctrinas... les servirán de apoyo para formar y robustecer la conciencia católica de los niños"15. La tarea de los docentes estaba impregnada por la ideología político-religiosa, que amparaba la exaltación del gobierno de los sublevados, a la vez que encorsetaba su misión. Según “el anunciado carácter de ensayo pedagógico con que fueron presentados los programas, no perseguía otro objetivo que controlar estrechamente la labor de un

13 "El Maestro Nacionalsindicalista", Revista Nacional de Educación, No 4 (1941): 101-104.

14 Boletín Oficial del Estado (BOE) n 172, de 19 de diciembre de 1938, 3036.

15 BOE no $172,3036$. 
colectivo sujeto ${ }^{16}$. El programa y la uniformidad de los contenidos curriculares reflejaban la idea del ministro consciente de que los maestros no tenían capacidad de modificarlo, pero tenían que gestionarlo restaurando la escuela tradicional española sobre "cimientos católicos y patrióticos"17. La consolidación del sistema educativo con un férreo control ideológico y fuerte adoctrinamiento del magisterio se proyectó en la educación de las nuevas generaciones de españoles ${ }^{18}$.

Durante el periodo bélico y, a la vez, de reconstrucción nacional era primordial lograr mantener el funcionamiento educativo, normalizar la enseñanza primaria y la actividad docente. Sin embargo, fue un proceso complejo debido a la depuración del magisterio y las dificultades económicas. Por otra parte, se llevó a cabo la reorganización del Ministerio de Educación y el establecimiento de nuevos organismos. Por Decreto de 29 de marzo de 1939 se creó el Instituto de Pedagogía San José de Calasanz que sustituía al Museo Pedagógico Nacional, y por Ley de 24 de noviembre de 1939 se estableció el Consejo Superior de Investigaciones Científicas, desplazando a la Junta de Ampliación de Estudios. El Instituto de Pedagogía adquirió notoriedad a partir de 1943 al asignársele la máxima tarea pedagógica, así se le encomendó la organización docente, la pedagogía así como la elaboración de material pedagógico ${ }^{19}$. Más tarde se fundó el Consejo Nacional de Educación, por ley de 13 de agosto de 1943. Fue un organismo clave que tenía carácter consultivo y ejerció una acción intensa sobre cuestiones decisivas de la educación, tales como las leyes, programas educativos, planes de estudio, libros de texto, material didáctico, creación de centros, personal docente, etc. con la misión de "regenerar y reformar la enseñanza en todos sus grados" 20 .

16 José Ramón López Bausela, , 337.

17 José Ramón López Bausela. 340.

18 José Ramón López Bausela, La escuela azul de Falange Española de las J.O.N.S.: Un proyecto fascista desmantelado por implosión (Santander: Dykinson / Ediciones Universidad Cantabria, 2017), 144.

19 María Dolores Peralta Ortiz, La escuela primaria y el magisterio en los comienzos del franquismo (Madrid: Universidad Pontificia de Comillas, 2012), 81-82.

20 María Dolores Peralta Ortiz, La escuela primaria y el magisterio, 85. 
Los libros pedagógicos eran aprobados por la Comisión Dictaminadora de Libros de Texto anexa al Consejo Nacional de Educación, que según la Orden de 6 de mayo de 1940 ampliaba sus competencias para que dictaminara sobre los libros de Pedagogía destinados a la formación del magisterio. Dicha Comisión se encargaba de los manuales escolares, desde agosto de 1938, pero sus facultades se extendieron a los textos de las Escuelas de Magisterio. No obstante, la Comisión Dictaminadora de Libros de Texto fue suprimida a través de la Orden de 9 de mayo de 1941 y pasaron a depender directamente del Consejo Nacional de Educación ${ }^{21}$.

De la misma manera en la enseñanza primaria, el programa educativo fue elaborado por las autoridades que durante el periodo bélico gestionaron la educación en la España en guerra. La estrategia fue desarrollar programas para redefinir el currículum escolar para que los maestros y maestras lo aplicaran con el objetivo de "restaurar la escuela tradicional"22. El diseño curricular afectó a toda la enseñanza básica, a todas las escuelas, y a los distintos niveles educativos, todos quedaron teñidos por la pedagogía de carácter patriótico y religioso. Añadir a lo anterior que la línea curricular prescribió unos contenidos específicos dirigidos a las niñas. Los programas escolares de 1938 sumaron las materias femeninas al currículo tradicional, de acuerdo con el rol fijado para las mujeres. En su aprendizaje el nuevo Estado pretendía, desde la escuela, formarlas como pequeñas mujeres para su misión de esposas, madres, administradoras del hogar y guardianas de los valores del nacionalcatolicismo ${ }^{23}$. Así los programas escolares de 1938 incluían la formación obligatoria específica para las escuelas de niñas, con el objetivo de adiestrarlas desde la infancia como pequeñas mujeres en los quehaceres de carácter doméstico. Los contenidos curriculares con los saberes femeninos (labores, economía doméstica y puericultura) como ámbitos de conocimiento sobre los que debía girar la educación de las niñas y, por ende, la formación inicial de las maestras. En este sentido el mensaje a las maestras era muy claro: "Date cuenta, maestra, del gran problema y pon todos tus afanes en esto. Más, infinitamente más, que la enseñanza de

21 María Dolores Peralta Ortiz, La escuela primaria y el magisterio, 88.

22 José Ramón López Bausela, Los programas escolares inéditos de 1938 en la España de Franco. El cerco pedagógico a la modernidad (Madrid: UNED/Universidad de Cantabria, 2012), 73-74.

23 José Ramón López Bausela, Los programas escolares inéditos de 1938, 63. 
cualquier otra cosa. Labores, economía doméstica, puericultura, los ejes y fundamentos de la escuela de niñas" ${ }^{24}$. La política de feminización diseñada por la Sección Femenina marcó la educación y la vida de las niñas y mujeres españolas. Las relaciones de género que implantó el régimen fueron similares a la de otros fascismos europeos (fascismo italiano y nacionalsocialismo alemán).

\section{Propuestas para Reformar los estudios de magisterio}

Entre 1936 y 1945 se realizaron una serie de modificaciones curriculares y reformas en los programas de formación adaptadas a las nuevas concepciones del magisterio. Hasta 1945, año en el que se promulga la Ley de Enseñanza Primaria, la formación inicial del magisterio respondió a soluciones inmediatas para resolver la preparación del alumnado que había iniciado sus estudios según el Plan de 1931 y atender la preparación inicial con una propuesta provisional durante los años de la guerra y posguerra. La evolución del currículum se refleja en los planes de estudio provisionales en el marco del periodo bélico.

En el contexto de las reformas educativas trazan el programa adaptado a las concepciones ideológicas y sus líneas maestras permiten analizar los principales sesgos del nacionalcatolicismo. La remodelación de los estudios de magisterio marcha paralela a las modificaciones efectuadas en la enseñanza primaria. En 1938 la Asesoría Técnica del Ministerio de Educación Nacional realizó un Informe sobre Escuelas Normales y Estudios ${ }^{25}$. La escuela rural y la escuela urbana son las únicas variantes de la escuela nacional; en función de ella se articulan los dos anteproyectos del magisterio. Las referencias para la elaboración de los nuevos diseños curriculares eran el Plan de 1914 y el de 1931. El plan de estudios de 1931 fue un punto de inflexión que genera desencuentros y rechazo en la medida que fue diseñado por el gobierno republicano y patrocinado por ideales demo- 
cráticos $^{26}$. Las revistas Escuela Española y El Magisterio Español recogen en sus editoriales los debates e incluyen las propuestas ${ }^{27}$.

\subsection{Dicotomía entre el magisterio urbano y el magisterio rural}

Mientras un sector apostaba por una formación vocacional-cultural otros apuntaban la importancia de dos modalidades de formación, una específica para zonas urbanas y otra para zonas rurales. De esta organización se derivarían dos tipos de centros, Escuelas de Magisterio Urbanas y Escuelas de Magisterio Rurales. En 1939 se presentaron al ministerio dos anteproyectos académicos. El Delegado de la Dirección de Primera Enseñanza de Madrid e Inspector de Enseñanza, Marcelino Reyero, planteaba la necesidad de ofrecer la adecuada preparación a los maestros y maestras en función del medio en el que iban a desempeñar su tarea. En este sentido publicó numerosos artículos donde argumentaba la importancia de la formación adaptada al medio geográfico. Al respecto decía que "El Maestro de la nueva España ha de tener una formación que responda a dos aspectos: cultural y formativo. Sus estudios han de tener un sentido teórico y práctico según el medio donde haya de aplicarlos, por lo cual han de ser, según se trate de Maestros Rurales o Maestros Urbanos, diferentes. Surgen como consecuencia dos clases de Maestros, rurales y urbanos, los cuales recibirán su formación en las Escuelas Normales de distinta clase, para que desde estas Escuelas salga la semilla adecuada para la educación de los niños españoles en las ciudades y en las aldeas"28.

La importancia de impulsar la escolarización en las áreas rurales, para que la infancia dispusiera de escuelas, era reflejo de la precaria escolarización en los pueblos y aldeas ${ }^{29}$. Este fue el discurso de los que defendían una formación inicial con una preparación elemental y especialización rural para el magisterio de estas zonas. Estimaban que se necesitaban maestros, pero

26 Josefina Álvarez hace una crítica, a colación de la reforma de la educación realizada en Francia, y escribe "vayamos con cuidado, que la delicadísima labor de educar es un problema, más de apóstoles que de eruditos a la violeta". Artículo publicado en la Revista Atenas, No 76, (1937): 294.

27 Escuela Española, № 65 (1941): 483; El Magisterio Español, no 6741 (1940): 935.

28 El Magisterio Español, No 6658 (1939): 267.

29 María Dolores Peralta, La escuela primaria y el magisterio, 111. 
elevar el rango profesional y académico no era una cuestión prioritaria en aquellas fechas. Había que instruir a la gente del pueblo para que surgieran vocaciones y a su vez enseñaran a sus gentes en su propio ambiente y para ese mismo ambiente. Sin embargo, había detractores que pensaban que la doble formación perjudicaba al colectivo, porque las dos categorías, separando a los maestros en urbanos y maestros rurales, dividirían al magisterio ${ }^{30}$. Los proyectos de formación rural y urbana planteaban una preparación común y otra específica en el currículum de preparación inicial. Este proyecto seguía el modelo de los Seminarios de Maestros de las Escuelas del Ave María que patrocinó Andrés Manjón ${ }^{31}$. La repercusión de su programa formativo constituye una aportación significativa en el marco de la educación española que responde a una situación real de necesidad pedagógica ${ }^{32}$. Un peculiar hito en la formación magisterial que algunos maestros consideraron oportuno aplicar siguiendo su modelo para impulsar los valores cristianos y la cultura del entorno. En el Consejo Nacional de Educación se debatieron estos dos modelos de preparación del magisterio de carácter cultural y especialización urbana o rural, pero a la Comisión Permanente no se le presentaron las dos modalidades. Así quedaba incluida la formación cultural en los estudios de magisterio. Tanto en los anteproyectos de 1939 como en otras propuestas posteriores se barajaba el régimen de internado para desarrollar la vocación de los educadores. Existían antecedentes que demostraban su eficacia, como la Residencia de Estudiantes de la Junta de Ampliación de Estudios, la experiencia de los Seminarios de las Escuelas del Ave María y las Academias de Pedro Póveda, y se pretendía recuperar la vocación a través de estas instituciones ${ }^{33}$.

El anteproyecto de la Comisión designada por Romualdo de Toledo planteaba la formación de maestros en las Escuelas de Magisterio y para los maestros rurales en las Escuelas de Magisterio Rurales. Estructuraban los estudios en dos cursos de formación cultural y dos cursos de especiali-

30 Petrus. “¿Hacia la creación de dos Magisterios?”, El Magisterio Español, Nº 6634, (1939): 6.

31 Andrés Palma Valenzuela, "Maestros del pueblo para el pueblo". Revista de Antropología Experimental, No 6 (2010): 63-70.

32 Andrés Palma Valenzuela, "Maestros del pueblo para el pueblo", 70.

33 "Ante todo: vocación”, El Magisterio Español, no 6696 (1940): 683. 
zación. El plan de estudios para el magisterio rural constaba igualmente de cuatro cursos. Las Escuelas de Magisterio Rurales tendrían como singularidad impartir la enseñanza en régimen de internado, al menos en parte del periodo de su formación, además tendrían un marcado carácter religioso, considerado un aspecto fundamental para su vocación, tal como se desprende del anteproyecto ${ }^{34}$. Respecto a la formación religiosa el texto recoge lo siguiente: "En cada internado habrá un Capellán que tendrá a su cargo la formación religiosa y moral en colaboración con el profesor de Religión de la Escuela Normal. Los alumnos recogerán la influencia educadora de los retiros y ejercicios espirituales por medios prácticos en los dos años de especialización"35.

La propuesta presentada por la asesora técnica del Ministerio de Educación Nacional, María Dolores Naverán (por encargo de Romualdo Toledo), se centró fundamentalmente en la escuela rural y en diseñar el perfil del magisterio para este tipo de escuelas, es decir, la formación de maestros y maestras rurales ${ }^{36}$. Partía de la realidad española, de la importancia del espacio rural, por lo que proponía los dos modelos independientes: rural y urbano. La formación sería diferente, con un currículum específico y, por tanto, en centros con identidad propia. La asesora en su estudio presta atención preferente al magisterio rural, con la identificación prioritaria de la Escuela de Magisterio Rural para formar maestros y maestras. La Escuela de Magisterio Rural femenina tenía el objetivo de formar maestras encargadas de instruir a las niñas de las escuelas rurales, como futuras mujeres cristianas para el hogar campesino. De ahí el currículo con materias específicas para enseñar a aprender a ser mujeres hogareñas.

En el proyecto María Dolores Naverán diseñó el modelo y plan de estudios, con organigrama completo, sus objetivos y fines. Sistematizó las competencias de las Escuelas de Magisterio Rurales, entre ellas señalaba la finalidad de mejorar las condiciones de vida del mundo rural a través

34 Archivo de la Fundación Universitaria Española (AFUE). "Vocación profesional”. Base XVIII. Anteproyecto de Ley de Bases de la Enseñanza Primaria y Normal.

35 AFUE. "Vocación profesional". Base XVIII. Anteproyecto de Ley de Bases de la Enseñanza Primaria y Normal".

36 María Dolores Peralta, La escuela primaria y el magisterio, 173-175. 
de la formación de maestros, tanto inicial como continua, y las actividades de extensión educativa-cultural para la población de las áreas consideradas rurales. Traza unas líneas generales para su funcionamiento en régimen externo, pero estimaba que los centros debían disfrutar de autonomía para adaptar el programa de estudios al entorno. A la sazón debían elaborar un proyecto con el programa a impartir que debía contar con la aprobación oficial. El cronograma general se correspondía con cinco años académicos, tres dedicados a la formación teórica y dos a la formación práctica. Una parte de las prácticas se desarrollaría en la escuela rural modelo y la otra parte en extensión educativa-cultural. Además puntualizaba la redistribución en ciclos de cinco meses, con un mes de vacaciones entre cada uno, para conocer el área en cada una de las estaciones. La estructura académica del sistema de formación para la enseñanza rural estaba compuesta por las materias de formación religiosa y formación patriótica igual que en el modelo urbano, materias culturales, materias didáctico-pedagógicas, materias de tipo sanitario, y materias específicas según la zona (por ejemplo, agraria, ganadera, pesquera) y prácticas de enseñanza a realizar en la "escuela rural modelo".

Uno de los requisitos de acceso era que el alumnado tuviera procedencia rural, y este podía ingresar a partir de los catorce años. Para la formación continua planteaba jornadas pedagógicas trimestrales, cursos breves de 15 días durante el verano, programas radiofónicos y publicaciones pedagógicas para mantener actualizado al magisterio, así como el envío de folletos y cuadernillos. Había correspondencia entre la formación del magisterio y la enseñanza primaria con énfasis para el espacio rural. Así se instrumentaron las nuevas propuestas de programas para responder adecuadamente a las necesidades concretas del alumnado en el campo: La idea de transformar las áreas rurales a través de la educación y de la contribución que podían realizar los maestros y maestras, siguiendo un plan de fundación de Escuelas de Magisterio Rurales para lograr estos objetivos. La finalidad principal consistía en mejorar la calidad de la formación docente de los futuros maestros y maestras rurales para que sus estudios fueran realmente los más apropiados a su función. Combinar el aprendizaje de las materias curriculares con los conocimientos de actividades agropecuarias, constituiría la base de la preparación de los futuros docentes. Lo característico 
de los egresados de las Escuelas de Magisterio Rurales era su identificación e integración en el mundo rural. Sin embargo, las propuestas de formación propia para el magisterio de escuelas rurales no prosperaron, quedaron en mero proyecto. En España no ha existido tradición en la formación específica del magisterio para áreas rurales, aunque sí la intención de preparar al magisterio que se destinaría a estas zonas, que por otra parte contaba con un importante censo escolar y poblacional.

\section{Modalidades de Escuelas de Magisterio}

La Ley de Enseñanza Primaria promulgada el 17 de julio de 1945, sintetizaba los principios programáticos del régimen político y tuvo un amplio alcance. Estuvo vigente durante casi veinte años, hasta que fue sustituida por la Ley de Enseñanza Primaria de 21 de diciembre de 1965 y esta, a su vez, por la Ley General de Educación de 4 de agosto de 1970, esta última representó un avance significativo aunque mantenía los pilares ideológicos del régimen.

El artículo 59 de la Ley de Enseñanza Primaria de 17 de julio de 1945, establece que las Escuelas de Magisterio se transformen "en espacios en los que se despierten y vigoricen las dotes vocacionales de los alumnos y el sentimiento religioso y humano de todo educador, así como un auténtico espíritu nacional en servicio de unidad de la Patria". Estas instituciones serían un sostén ideológico para el régimen bajo la influencia del fascismo y el catolicismo. Es decir, del nacionalcatolicismo ${ }^{37}$. Estas escuelas se hallaban "bajo la advocación de Jesús", según disponía el artículo 60 del Reglamento de Escuelas del Magisterio de 7 de julio de 1950 y la Ley de Educación Primaria de 17 de julio de 1945. Título II, Capítulo 1º . Art.16. ${ }^{38}$ La simbología religiosa era una de las notas características en la vida académica. Tanto los Crucifijos e imágenes de la Virgen María presidían las dependencias de los Centros, como también el retrato del Jefe del Estado

37 Adolfo Maíllo, Educación y revolución. Los fundamentos de una educación nacional (Madrid: Editora Nacional, 1943).

38 Artículo 60 del Reglamento de Escuelas del Magisterio, Decreto de 7 de julio de 1950 (BOE 4 de agosto) y la Ley sobre Educación Primaria de 17 de julio de 1945. Título II, Capítulo 1º. Art.16; Capítulo II, Art. 59. 
omnipresente en todas las aulas (Reglamento de Escuelas del Magisterio de 7 de julio de 1950. Art. 2). La Religión y la Formación del Espíritu Nacional constituían las materias básicas del currículo.

De acuerdo con la Ley de 1945, según establece el artículo 62 de dicha ley, existieron tres modalidades de Escuelas de Magisterio: 1) Escuelas de Magisterio públicas sostenidas por el Estado; 2) Escuelas de Magisterio privadas y 3) Escuelas de Magisterio de la Iglesia. Las escuelas tendrían una organización diferenciada según el sexo tanto en sus instalaciones, como en la organización y disciplina ${ }^{39}$. Estas escuelas tenían que acatar la normativa para su funcionamiento, incluso aquellas sostenidas por entidades privadas. El Reglamento disponía que el Maestro tenía que ser "ante todo, un ministro de la verdad, que es vida en Dios" y concluía declarando que lo que importaba era "desarrollar en sus detalles lo que fue innovación fundamental de la Ley, a saber, la aplicación a las Escuelas del Magisterio de los principios cristianos de libertad de enseñanza, merced a los cuales encuentran ancho cauce para su expansión las Escuelas de la Iglesia y las privadas, con lo que se amplía su cantidad y calidad el marco de la formación del Maestro en España, con mejores y más esperanzadoras perspectivas para el espíritu católico nacional que en ningún otro país del mundo" (Decreto de 7 de julio de 1950). Las Escuelas de Magisterio del Estado venían funcionando desde el siglo XIX, dependientes de organismos oficiales, y existían en las distintas provincias españolas. En los casos donde se carecía de centros de enseñanza superior equivalían a pequeñas universidades y ofrecían preparación a los jóvenes de ambos sexos.

Por lo que se refiere a las Escuelas del Magisterio de la Iglesia, la legislación concede al estamento eclesiástico la potestad para crear sus propias instituciones formadoras de maestros y maestras al amparo de la legislación ${ }^{40}$. Las Escuelas Normales creadas y regidas por Instituciones Eclesiásticas serían, según el artículo 62 de la Ley de Educación Primaria de 17 de julio de 1945, Escuelas de la Iglesia. El reconocimiento de este derecho

39 Ley sobre Educación Primaria de 17 de julio de 1945 (BOE nº 199, de 18 de julio). Capítulo II. Art. 62.

40 José Ruiz Rico, El papel político de la Iglesia Católica en la España de Franco (1936-1971) (Madrid: Tecnos, 1977), 73. 
fue un elemento para reproducir sus esquemas ideológicos, su apostolado católico, junto a los valores patrióticos del régimen. El magisterio desde su óptica equivalía a un sacerdocio y había que "formar a quienes van a formar". La Iglesia a la vez resolvía el problema de sus docentes, pues no contaba con titulados suficientes entre sus miembros para atender la enseñanza de todo el alumnado de sus centros educativos. Entre sus estudiantes había miembros de la comunidad religiosa junto a los seglares. Si bien despertaron vocaciones religiosas también magisteriales. Se proyectaron especialmente a captar aspirantes entre los sectores populares y en familias de economía modesta. Con limitados recursos y con el apoyo de algunas instituciones lograron mantenerse, ofreciendo formación magisterial a los sectores menos favorecidos, además de los miembros de sus propias órdenes religiosas. Los egresados y egresadas podían ejercer la enseñanza en los centros de la Iglesia y de patronato. Sin embargo, para poder desempeñar la profesión en las escuelas públicas nacionales debían superar unas pruebas de conjunto en las Escuelas de Magisterio del Estado.

La Ley de 1945 autorizó la creación de escuelas privadas y de la Iglesia, a la vez que recomienda el fomento del régimen colegial (artículo 64). Este modelo facilitaba la formación religiosa y patriótica, completada después con la asistencia obligatoria a campamentos y albergues. También el establecimiento de una Residencia para que el alumnado hiciera vida de internado o en su defecto "mediopensionado" o "externado" para que toda la formación y actividades de estudio se realizaran en el centro. La normativa de 1945 y el reglamento de Escuelas Normales de 1950 regularon la vida de las escuelas hasta la reforma de 1967, es decir, a lo largo de dos decenios. La eficacia y vitalidad de su actividad se reflejó en el avance de las Escuelas de Magisterio de carácter católico y en el número de alumnado egresado. Comoquiera que existía segregación por sexos, funcionaban escuelas de magisterio femeninas ${ }^{41}$ y escuelas de magisterio masculinas ${ }^{42}$, pero destacaban tanto en matrícula como en número de centros las insti-

41 Josefa Zaballos Crespo, Origen y evolución histórica de la escuela universitaria "Don Bosco", (tesis doctoral dirigida por María del Carmen Labrador Herráiz. Universidad Complutense de Madrid, 2003), 221-224.

42 Josefa Zaballos Crespo, "Una mirada en la historia del CES Don Bosco de Madrid", Educación y futuro: Revista de investigación aplicada y experiencias educativas, No 18 (2008): 225-228. 
tuciones femeninas. Tanto las escuelas femeninas como masculinas, pertenecientes a la Iglesia, seguían un programa específico que facultaba a los titulados para ejercer en sus propios colegios. Para obtener la titulación oficial y poder ejercer la docencia en las escuelas nacionales de entonces, los egresados y egresadas tenían que examinarse de una reválida en las Escuelas de Magisterio del Estado. La expansión de las Escuelas del Magisterio de la Iglesia fue muy rápida; estas las instituciones se multiplicaron por toda la geografía española, incluidos los territorios insulares. Distintas órdenes religiosas instituyeron Escuelas de Magisterio (Carmelitas, Escolapias, Hermanas de la Caridad, Salesianos, Teresianas, etc.). Las primeras escuelas que comenzaron a funcionar fueron las Carmelitas de la Caridad y se establecieron en distintas capitales de provincias (Valencia, Zaragoza, Tarragona, Madrid, Barcelona). Se inauguraron en 1948, pero el proceso de instauración siguió en una línea de extensión progresiva, de manera que en el año 1951 había 44 escuelas en funcionamiento; cantidad que representaba el $41 \%$ de las Escuelas de Magisterio, con un espectacular incremento de Escuelas de Magisterio de la Iglesia masculinas y Escuelas de Magisterio de la Iglesia femeninas. Entre 1948 y 1968, sumaron un total de 118 Escuelas del Magisterio de la Iglesia. La región que contó con mayor número fue Andalucía con 22 escuelas, siendo Valencia con 9 centros la capital de provincia con mayor número de Escuelas del Magisterio de la Iglesia, situándose incluso por delante de Madrid (8). También funcionaron Escuelas de Magisterio de la Iglesia en las provinciales insulares, tanto en Baleares como en Canarias. Sin embargo, en las provincias de Cuenca, Teruel y Toledo no existieron Escuelas del Magisterio de la Iglesia ${ }^{43}$. La matrícula de alumnado era importante aunque no elevada. En algunos centros el total de alumnado era en torno a 100 y en otros entre 60 a 80 en cada una de ellas. En total se alcanzaron 25 mil titulados egresados entre las escuelas masculinas y femeninas, formados con una "pedagogía de inspiración cristiana”. Sin embargo, no en todas las provincias españolas funcionaron escuelas de ambos sexos. En esta época de crecimiento aumentó considerablemente el número de Escuelas de Magisterio que "pretendían

43 Josefa Zaballos Crespo, Origen y evolución histórica de la escuela universitaria "Don Bosco", tesis doctoral, 198. 
transformar la sociedad" y cuyo objetivo era erradicar el analfabetismo ${ }^{44}$, pero el índice de egresados no cubría las demandas de maestros y maestras que se necesitaban para atender las necesidades de la educación primaria.

Más tarde, al margen de lo anterior, se crearon las Escuelas de Magisterio Nocturnas, a imitación de los Institutos Nocturnos para personas adultas que venían funcionando desde mediados de los años cincuenta, para atender a la población estudiantil que no podía cursar estos estudios por el sistema ordinario. El ministro Jesús Rubio García-Mina creó las Escuelas de Magisterio Nocturnas, con carácter experimental y de ensayo, con secciones masculina y femenina (Decreto de 20 de junio de 1958) en las mismas condiciones académicas que las Escuelas de Magisterio Diurnas (requisitos de ingreso, programas, exámenes, etc.). Inicialmente se establecieron en Madrid, cuyas enseñanzas se organizaron de acuerdo con la Orden Ministerial de 29 de septiembre de 1958. En el curso 1958-1959 comenzó el primer año de dichos estudios de acuerdo con "las necesidades específicas y normas pedagógicas y didácticas adecuadas a estas Escuelas nocturnas". La Orden de 6 de octubre de 1960 organizó las enseñanzas en tres años académicos para la carrera en la Escuela de Magisterio Nocturna y Experimental de Madrid. La actividad docente se desarrollaba en las últimas horas de la tarde y primeras de la noche, con el objetivo de facilitar el acceso a estos estudios a quienes durante el día trabajaban y por constituir esta la única fuente de ingresos. La planificación seguía el modelo académico de los institutos con la organización de las clases en jornadas de cuatro horas didácticas, divididas en cinco clases de cuarenta y cinco minutos, ininterrumpidas de seis a diez de la noche. Es preciso clarificar el matiz del perfil del alumnado, pues "a diferencia del estudiante que trabaja se trataba de un trabajador que estudia". Habitualmente eran trabajadores cuyas edades oscilaban entre los 20 y 30 años, muchos con responsabilidades familiares o faltos de recursos, que pretendían mejorar su formación cultural y profesional pero tenían dificultades para seguir la modalidad de enseñanza libre. Las Escuelas de Magisterio Nocturnas fueron la solución para ofrecer alternativas al alumnado que desempeñaba actividad laboral y no podía asistir a los centros oficiales. Así se especializaron las Escuelas

44 Josefa Zaballos Crespo, Una mirada en la historia del CES Don Bosco de Madrid, 53. 
de Magisterio Nocturnas en la capacitación de alumnos que trabajaban, los cuales concurren en horario nocturno para compatibilizar el trabajo con su formación académica. Además dicha capacitación profesional les ofrecía la posibilidad de un trabajo inmediato que mejoraba su condición o posición socioeconómica. La propia extracción social de los aspirantes, procedentes de las capas medias bajas y bajas, hacía atractiva la profesión magisterial. También para resolver la masificación de los centros la oferta de plazas en los centros nocturnos contribuyó a la redistribución de estudiantes. Estos centros se establecieron en las principales provincias (Madrid, Barcelona y Valencia) donde había una mayor demanda. La Escuela de Magisterio Femenina "Santa María” se creó en Madrid por Orden de 28 de julio de 1961 (BOE. de 19 de agosto de 1961), dada la elevada matrícula de la Escuela "María Díaz Jiménez" y para ampliar la oferta de estos estudios además de establecer otra Escuela en Madrid, aunque era solo para mujeres. Años más tarde, por la Orden de 19 de octubre de 1967 (BOE. de 30 de octubre de 1967) se establecieron en dicha escuela los estudios nocturnos.

Los cambios y reformas en los estudios de magisterio fueron notorios a partir de $1960^{45}$. La Ley de Enseñanza Primaria de 21 de diciembre de 1965 (BOE de 23 de diciembre) concedió importancia a los programas de formación del Magisterio Primario, junto a la modalidad de estudios nocturnos para aquellos aspirantes que no pudieran asistir por circunstancias laborales o personales (artículo 63) previa autorización del Ministerio de Educación Nacional. El artículo 62 permitía la expedición de títulos a las Escuelas de Magisterio de la Iglesia siempre que cumplieran con los requisitos oficiales. También el Ministerio a través de la ley fijó, de acuerdo con las Delegaciones Nacionales de Juventudes y Sección Femenina, los cursos de capacitación en las «actividades juveniles de tiempo libre» que habrán de realizar los alumnos para la obtención del título de Maestro. Sin embargo, a pesar de ciertos avances, dicha ley mantenía la separación de sexos (Art.14 de la ley) y un currículo diferenciado. Las materias específicas para cada sexo se impartirían por separado (Art. 61). Las Escuelas de

45 Miguel Beas, "Formación del magisterio y reformas educativas en España: 1960-1970", en Profesorado. Revista de curriculum y formación del profesorado, No 14 /1 (2010): 401-402. 
Magisterio de la Iglesia se adaptaron a la normativa en aras de cumplir con su cometido pedagógico, respondieron a los requisitos establecidos para los nuevos planes de estudio de acuerdo con las disposiciones oficiales del ministerio ${ }^{46}$. Posteriormente, algunos de estos centros se reorganizaron y fusionaron, al unificarse las escuelas masculinas y femeninas, y otros desaparecieron $^{47}$.

El régimen de enseñanza en la época permitía alcanzar la titulación a través del sistema de enseñanza libre o no oficial. Las Escuelas de Magisterio acogieron dos modalidades de enseñanza, oficial y libre. La diferencia entre una y otra radicaba en que mientras en la primera se asistía regularmente a clase, en el segundo caso no se asistía. El alumnado solamente acudía a las fechas de convocatorias de exámenes y se preparaban en academias, clases particulares o por sí mismos. Además el estudiantado tenía un calendario de exámenes diferenciado según fuera su adscripción. Esta doble modalidad de enseñanza permaneció funcionando hasta la entrada en vigor de la Ley General de Educación de 1970 y el Plan de Estudios de 1971. La referida Ley General de Educación de 1970, supuso la elevación del rango de los estudios profesionales de magisterio a diplomatura universitaria. A tal fin dispuso la integración de las Escuelas del Magisterio en la Universidad, pasando a denominarse Escuelas Universitarias de Formación del Profesorado de Enseñanza General Básica. El programa de estudios se unificó así como el espacio académico, suprimiendo la segregación sexual al menos a nivel teórico. Las Escuelas de Magisterio de la Iglesia siguieron idéntico modelo y se adscribieron a sus respectivos distritos universitarios como Escuelas Universitarias ${ }^{48}$.

\section{Masculinidad y feminidad en el CuRrículo de los estudios de MAGISTERIO}

El discurso político prestaba atención preferente a las nuevas generaciones y las instituciones de Falange se ocuparon de reforzar su función. A las

46 Josefa Zaballos Crespo, Una mirada en la historia del CES Don Bosco de Madrid, 54-55.

48 Josefa Zaballos Crespo, Una mirada en la historia del CES Don Bosco de Madrid, 63. 
mujeres se les orientaba al hogar, exaltando la domesticidad, mientras a los hombres se les dirigía hacia la vida laboral y la defensa de la patria. La Sección Femenina fue el organismo que se ocupó de la reeducación femenina y desde las esferas del Frente de Juventudes primero y la Organización Juvenil Española (OJE) después de la reeducación la masculina. A lo anterior añadir que la construcción del género se planteaba desde posiciones tradicionales en donde se perfilaba la identidad de los hombres en la esfera pública y la identidad de las mujeres en la esfera privada, vinculadas a su papel en la familia. De manera que los hombres desempeñaban el trabajo remunerado y gozaban de los privilegios otorgados por el patriarcado. Pero las mujeres desarrollaran su rol en el hogar familiar, subordinadas al padre o al marido, aunque les competía un macro rol como organizadora de las actividades domésticas, esposa, educadora de los hijos y cuidadora de la familia. A excepción de las maestras y las enfermeras, consideradas como unas profesiones femeninas continuadoras del hogar, su misión se situaba en la vida privada, invisible y silenciosa del hogar ${ }^{49}$.

El principal instrumento de la política de masculinización y de la política de feminización la ejerció el gobierno a través de las instituciones de la Falange. En la estructura política del régimen la Falange gozaba de una situación privilegiada ${ }^{50}$. La política de la juventud y las competencias educativas las mantuvo hasta su disolución en $1977^{51}$. El papel socializador, su política generacional innovadora y el protagonismo político de la juventud garantizaron su éxito, al percibir un discurso más avanzado y progresista frente a los conceptos tradicionales de otras organizaciones ${ }^{52}$. Tanto el Frente de Juventudes como la Organización Juvenil Española y la Sección Femenina contribuyeron a la construcción de modelos de masculinidad y feminidad de la época según los principios del movimiento nacional, hecho que revierte en la construcción de las identidades masculinas y femeninas en el franquismo.

49 Nahir Lagos Arias, "Memorias de una educación represiva", Revista Murciana de Antropología, No 23 (2016): 205-206.

50 José Ignacio Cruz Orozco, "Falange, Frente de Juventudes y el nuevo orden europeo. Discrepancias 106 y coincidencias en la política de juventud durante el primer franquismo", Revista de Educación, $\mathrm{N}^{\circ}$ 357 (2012): 518.

51 José Ignacio Cruz Orozco, "Falange, Frente de Juventudes y el nuevo orden europeo...”, 519-520.

52 José Ignacio Cruz Orozco, "Falange, Frente de Juventudes y el nuevo orden europeo...", 520. 
El aprendizaje de la masculinidad y el aprendizaje de la feminidad se sustentaba en la raíz "del influjo de una serie de mediaciones subjetivas y culturales... que influyen de una manera determinante en la construcción de las identidades humanas" 53 . A la juventud española se le ilusionaba con los mensajes políticos que anunciaban una buena nueva. Los discursos y arengas imbuidos por el nacionalcatolicismo movilizaban los ideales de los jóvenes, alentados por el afán de ser útiles o de servir a la patria, según fueran del sexo femenino o masculino. Desde la escuela fueron obligados a aprender las materias básicas, tanto la Historia como la Religión y la Formación Política, materias cargadas de ideología, con exaltación de valores, con el objetivo de mentalizarlos. Se actuaba sobre las subjetividades para aleccionarlos e inculcarle conductas patrióticas diferenciadas según el sexo. El franquismo promocionó el ideal de mujer y el ideal de hombre, que pretendía implantar a través de la educación. La adjudicación de arquetipos tradicionales en función del género, con un significado diferencial de los comportamientos y tareas asignadas a uno y otro sexo, imponía una jerarquía patriarcal y prácticas desiguales discriminatorias. Los roles de la sociedad patriarcal se reflejaron en la educación, que perpetuaron las diferentes misiones correspondientes a mujeres y hombres en la sociedad. Destacar el apego a prejuicios y estereotipos reiterados de forma diversa fue uno de los rasgos del franquismo. Se construyó un nuevo modelo de mujer basado en los arquetipos decimonónicos que sustentaba la sociedad tradicional ${ }^{54}$. La función exclusiva de las mujeres era la dedicación al hogar de forma gratuita. Se legisló en este sentido porque se planeaba un futuro donde "debía ser, ante todo, ama de casa" y no traspasar la frontera doméstica ${ }^{55}$. En esta etapa se consolidaron actitudes culturales en torno a la feminidad y la masculinidad; se normalizaron conductas discriminatorias junto a la pérdida de derechos cívicos, que se prolongaron en el tiempo y que han tenido consecuencias negativas para las mujeres.

53 Carlos Lomas, “¿La escuela es un infierno? Violencia escolar y construcción cultural de la masculinidad", Revista de Educación, No 342 (2007): 90.

54 Juan Carlos Manrique Arribas, "Incidencia del ideal de mujer durante el franquismo en el ámbito de la familia y la actividad física", Feminismo/os, No 23 (2014): 47-68.

55 Eider de Dios Fernández, "Domesticidad y familia: ambigüedad y contradicción en los modelos de feminidad", 26. 
El Frente de Juventudes, el equivalente masculino de la Sección Femenina, a partir de 1940 se encargó de la formación política, física y premilitar de los jóvenes españoles, así como de la docencia de la materia de Trabajos Manuales. En sintonía con los postulados del régimen y el modelo de hombre impartían sus enseñanzas en las Escuelas de Magisterio, en los institutos de enseñanza media (secundaria) y la universidad. Con igual inspiración falangista, el papel del hombre que preconiza el Frente de Juventudes se caracteriza por virtudes como la lealtad o el sentimiento de servicio a la patria. El deporte y la educación física se consideraban instrumentos básicos para el adoctrinamiento de los jóvenes, así como el acatamiento de la autoridad y la obediencia al ideario del régimen con una estructura militar. Al Frente de Juventudes le sucedió en 1960 la Organización Juvenil Española (OJE). Ambos impartían una formación de acuerdo con el ideario propio del régimen: el carácter militar, patriótico y confesional (basado en la fe católica) primordial para la defensa de la patria. La formación de los alumnos de magisterio resultó esencial, en el sentido de que los egresados se encargarían de la formación de las nuevas generaciones de hombres que necesitaba la patria. Para el caso de los maestros también la Falange se ocupaba de la formación de las materias específicas. Los hombres fuertes, viriles, sin afectos y emociones, respondían al arquetipo tradicional de masculinidad, unos estereotipos reforzados a través de la educación. Los signos de la masculinidad tradicional se transmitían en las lecturas, textos, educación física, mensajes, imágenes y comportamientos.

La Sección Femenina se encargó de diseñar un currículo para la formación de las maestras acorde con el modelo de mujer. En la educación para las mujeres se significó en el desarrollo del prototipo de mujer que precisaba la España de entonces. Como organismo afín al régimen franquista exaltó el patriotismo y la religiosidad a la vez que fomentó la pedagogía y técnicas de educación física. La Sección Femenina tenía competencias en varias materias consideradas importantes en su proceso de aprendizaje y preparación docente. Entre ellas se indica la educación física, la formación del espíritu nacional o política y la macromateria de Labores que encerraba la economía doméstica, puericultura, corte y confección....

La normativa fijó objetivos distintos en función del sexo y de los roles 
asignados. Se admitió una educación diferente para cada sexo y, a través de ella, se diseñaron roles masculinos y femeninos. Se aplicaba una enseñanza sexista y segregada, con formación diferenciada entre maestros y maestras, para atender a los roles diferenciados reflejo de la sociedad española del momento. El programa de estudios de carácter sexista se consolidó y se mantuvo vigente hasta la Ley de 1970 en todos los niveles educativos y, por ende, estaba presente en la formación del magisterio. El franquismo aportó una identidad femenina y encauzó su política de género para fomentar la imagen tradicional de la mujer en el hogar, como esposa, madre y educadora de los hijos ${ }^{56}$. Para ello trazó una política natalista, de promoción del hogar y de la maternidad, y promulgó leyes que limitaban la participación de las mujeres en el mercado de producción, reduciéndola prácticamente a la economía doméstica. De manera que reconstruyó el perfil femenino con base en el rol establecido por la sociedad para las mujeres en relación con los valores del patriarcado ${ }^{57}$. El matrimonio "constituía la plenitud de la feminidad por excelencia" ${ }^{58}$. Esta política, semejante a la que desarrollaron los regímenes europeos, tanto los regímenes totalitarios como los no totalitarios, tras la Primera Guerra Mundial. Después del conflicto bélico, buena parte de la población femenina, hizo frente a la realidad consciente de su papel, por la despoblación motivada por la pérdida de tantos hombres en la guerra y el exilio. Las mujeres españolas, como las europeas de las dos posguerras mundiales, asumieron en esos momentos la misión encomendada políticamente a la población femenina. Las mujeres fueron protagonistas, en la reconstrucción de la sociedad a través de la natalidad y, en algunos casos, de reinserción en la sociedad de los que habían sufrido los efectos de la guerra. Según afirman algunas expertas esto explica el alto porcentaje de vinculación entre las mujeres y el franquismo ${ }^{59}$.

Las ideas doctrinarias marcaron una imagen estructurada, aceptada de for-

56 Matilde Peinado y Jose Luis Anta, "Educar para el matrimonio en femenino: modelos y prácticas en la literatura de posguerra", Revista Athenea Digital, No $13 / 2$ (2013): 35-46.

57 Matilde Peinado, "Las mujercitas" del franquismo: Cómo enseñar y aprender un modelo de feminidad (1936-1960), Estudios Feministas, No 24/1 (2016): 282.

58 Matilde Peinado, "Las mujercitas" del franquismo, 288.

59 Angela Cenarro Lagunas, "Género y ciudadanía en el Franquismo". Ayer, No 102, (2016): 13-21; Angela Cenarro Lagunas. "Miradas y debates sobre la violencia franquista". Ayer, No 91 (2013): 241-253. 
ma generalizada, extendieron el perfil del "buen ciudadano" y la "buena mujer" de acuerdo a sus principios ideológicos ${ }^{60}$. Unos prototipos que marcaron el ideal de mujer anclada en valores de carácter tradicional y para ello tenía que recibir la formación adecuada ${ }^{61}$. Se argumentaba, con un discurso de carácter biológico, según el cual había diferencias congénitas específicas entre los hombres y las mujeres. En los hombres se desarrollaba más la inteligencia y en las mujeres, la sensibilidad. Por esta razón justificaban que los hombres tenían capacidad para desarrollar diversas actividades en la esfera de lo público y las mujeres, en el ámbito privado en armonía con el cuidado del hogar así como la crianza y educación de los hijos. Con base en estos postulados se fortalecía la subordinación de las mujeres, se eliminaba la autonomía, su capacidad de decidir por sí mismas y su integración en el espacio público. La elaboración de un diseño curricular diferenciado según el sexo, estimulaba a las mujeres para dedicarse al hogar, y a los varones para seguir estudiando, según convenía a la sociedad dirigente. Desde la escuela las niñas recibían una formación específica como pequeñas mujeres y orientada al hogar ${ }^{62}$. Para diseñar una educación acorde al papel que se esperaba de la mujer, se elaboró un currículum con asignaturas específicas para niñas tales como Hogar (que incluía Labores, Economía doméstica, Puericultura, etc.), Gimnasia o Educación Física y Formación del Espíritu Nacional, que comenzaban en la enseñanza primaria y se mantenían a lo largo de todo el ciclo educativo, con el objetivo de completar su formación para ser una perfecta ama de casa.

La formación del magisterio se caracterizó por un marcado carácter sexista, además de patriótico e ideologizado como hemos expresado anteriormente. En la formación de las maestras se reforzaron los roles y mensajes

60 Juan Carlos Manrique Arribas, Incidencia del ideal de mujer durante el franquismo, 51.

61 Juan Carlos Manrique Arribas, Incidencia del ideal de mujer durante el franquismo, 52, Juan Carlos Manrique, Víctor Manuel López, Luis Torrego y Roberto Monjas, "La labor formativa desarrollada por la Sección Femenina de la Falange en la preparación de sus mandos e instructoras durante el período franquista”, Historia de la Educación. Revista Interuniversitaria, 27 (2008): 347-365; Juan Carlos Manrique Arribas, "Actividad física y juventud en el franquismo (1937-1961)", Revista Internacional de Medicina y Ciencias de la Actividad Física y el Deporte, No 14 / 55 (2014): 442-443.

62 Eider de Dios Fernández, "Domesticidad y familia: Ambigüedad y contradicción entre los modelos de feminidad en el franquismo", 23-46. 
relativos a la feminidad y dedicación al hogar ${ }^{63}$. Para atender a los roles diferenciados, reflejo de la sociedad española del momento, se instruye a maestras y maestros a través de una enseñanza sexista y segregada ${ }^{64}$. En el caso de la formación de maestras "Se enseñó y se aprendió para lograr el bienestar de los otros"65. La marcada presencia de la línea curricular específica para las maestras, con unos contenidos específicamente femeninos y dirigidos a las mujeres, dado que tenían la obligación de enseñar a las niñas, futuras mujeres, en su propósito de enseñarlas a "ser mujeres". Tanto la Ley de Enseñanza Primaria de 1945 como la Ley de Enseñanza Primaria de 1965 establecieron un currículo diferenciado para la escuela de enseñanza primaria de niños y niñas. Del mismo modo se fijó la diferencia curricular para la formación de maestros y maestras en los planes de 1942, 1945, 1950 y 1967. Se diseñaron actividades y contenidos diferentes para alumnos y alumnas en las asignaturas de Formación del Espíritu Nacional, Trabajos Manuales y Educación Física, así como las asignaturas destinadas exclusivamente para las alumnas como Hogar. Dicha diferenciación legitimó la masculinidad y feminidad. Durante todo el franquismo, excepto en el Plan de 1971, se marcó la diferencia curricular de género, tanto en los contenidos como en los espacios académicos. En la formación inicial de las maestras la materia de Labores incluía una amalgama de contenidos tales como: hacer vainica, diversos puntos de aguja, el zurcido de prendas ordinarias, sentar pedazos, ojales y colocar botones; aprendizaje de algunas tareas domésticas como la limpieza del hogar, la higiene y comidas con variedad de guisos. La materia de Labores formó parte de los programas de magisterio femenino pero también tenía presencia en todos los niveles educativos de forma obligatoria hasta la promulgación de la Ley General de Educación (1970). También la materia de Economía Doméstica fue clave en la difusión de la identidad femenina. Los contenidos que figuran

63 Miryam Carreño y Teresa Rabazas Romero, "Sobre el trabajo de ama de casa. Reflexiones a partir del análisis de manuales de Economía doméstica”, Revista Complutense de Educación, No 21/1 (2010): 62.

64 Aurora Morcillo, "El género en lo imaginario. El "ideal católico femenino" y estereotipos sexuados bajo el franquismo", en Represión, resistencias, memoria. Las mujeres bajo la dictadura franquista Mary Nash (ed.):, (Granada: Comares Historia, 2013), 71-90; Eider de Dios Fernández, “"Las que tienen que servir» y las servidas. La evolución del servicio doméstico en el franquismo y la construcción de la subjetividad femenina,". Revista Historia Autónoma, No 3 (2013): 97-111.

65 Miryam Carreño y Teresa Rabazas Romero, "Sobre el trabajo de ama de casa", 68. 
en los manuales de Economía Doméstica, amparados en el rol tradicional, construyen la identidad femenina e inculcan esas ideas en la educación de las mujeres ${ }^{66}$. De ahí su importancia en la formación de maestras, tal como expresan Myriam Carreño y Teresa Rabazas: "Los planes de estudio para las maestras constituyeron el marco imprescindible en el que se desarrollaron estos manuales. La obligatoriedad del aprendizaje de las enseñanzas específicas para las mujeres, les dieron vida y les concedieron autoridad" ${ }^{\prime \prime}$.

Los planes de estudio de magisterio incluyen la formación física y la Falange era la responsable de la elaboración de los programas académicos. La Educación Física era una materia obligatoria que evoluciona junto al currículo formativo y sus enseñanzas estaban a cargo del personal instruido por la Falange masculina o Falange femenina y nombrada al efecto para desempeñar la docencia. La Educación Física igualmente era una materia diferenciada por sexos. La Educación Física femenina seleccionaba el tipo de actividad y de ejercicios, prohibía determinados deportes por considerarlos no aptos para las mujeres. Los programas didácticos se orientaban a hacer más femeninas a las mujeres, evitar su masculinización y contribuir a su preparación física en función de su futura maternidad. De manera que la educación Física tenía connotaciones fisiológicas e higienistas. Es decir, que presentaba un sentido biológico "utilitario" y respondía a esquemas ideológicos ${ }^{68}$.

La Ley de 1945 respecto a la Educación Física para los alumnos pretendía "formar una juventud fuerte, sana, disciplinada" y una preparación "para la superior formación intelectual o para la vida profesional del trabajo en la industria y el comercio o en las actividades agrícolas"69. Para las alumnas concretaba que se las capacitaría específicamente "para la vida del hogar,

\footnotetext{
66 Miryam Carreño y Teresa Rabazas Romero, "Sobre el trabajo de ama de casa", 62.

67 Miryam Carreño y Teresa Rabazas Romero, "Sobre el trabajo de ama de casa", 69.

11268 Teresa Rabazas Romero. "La educación física del Magisterio femenino en el Franquismo". Revista Complutense de Educación, 171.

69 Ley de Educación Primaria de 17 de julio de 1945; Boletín Oficial del Estado, No 199, 18 de julio de 1945, 387-388.
} 
artesanía e industrias domésticas" ${ }^{70}$. El programa curricular evoluciona en los distintos planes de estudio de acuerdo con el momento político. Para el caso de las mujeres en el primer franquismo tenía carácter científico "biomédico, fisiologista" y en el segundo tenía una orientación "técnico-higienista" con el objetivo profesional ${ }^{71}$. Su rótulo se modifica en los distintos planes de estudio: Gimnasia y Recreos dirigidos (Plan 1942), Educación Física (Plan 1945); Educación Física y Deportes (Plan 1950), Educación Física (Planes 1967 y 1971).

El discurso de la Sección Femenina se fue adaptando a las exigencias políticas que el régimen iba demandando para la formación de las mujeres. Durante los años cincuenta y sesenta, seguían legitimándose aquellas funciones sociales que las mujeres venían desarrollando en el ámbito privado, en el hogar familiar, relacionadas al modelo educativo femenino imperante a lo largo de la historia. En estos años la sociedad española evoluciona y la mentalidad se va transformando. No obstante, de forma progresiva los comportamientos se fueron adaptando a los cambios, con una mayor flexibilidad hacia las actividades que inician las mujeres. Se acepta de manera paulatina la incorporación laboral y el ejercicio profesional de aquellas féminas que acceden al trabajo remunerado. Esa actitud fue también favorable al acceso a las universidades y diversas titulaciones, aunque había espacios académicos no permitidos. Especialmente a partir de 1970 y la promulgación de la Ley General de Educación, se abrían espacios inimaginados y el camino hacia la apertura hacia nuevos horizontes que anunciaban la etapa final de la dictadura. La progresiva implantación de la enseñanza mixta significó la convivencia física de alumnos y alumnas, si bien no se cuestionaba el mantenimiento de dos modelos educativos bien diferenciados en función del sexo, posibilitó el lento pero progresivo cambio de actitudes.

70 Ley de Educación Primaria de 1945, 387-388; María del Mar del Pozo Andrés y Teresa Rabazas Romero, "Políticas educativas y prácticas escolares: la aplicación de la ley de enseñanza primaria de 1945 en las aulas”,. Bordón. Revista de pedagogía, No 65 / 4 (2013): 10.

71 Teresa Rabazas Romero, "La educación física del Magisterio femenino en el Franquismo", 194. 


\section{Conclusiones}

El franquismo utilizó la educación para sustentar la legitimidad del régimen. La consolidación de un sistema educativo con un férreo control ideológico y fuerte adoctrinamiento del magisterio se proyectó en la educación de las nuevas generaciones de españoles. Los anteproyectos y las propuestas formativas trataban de responder a la realidad de la población española de la posguerra. El énfasis en las zonas rurales de los primeros momentos se diluyó y no prosperaron las iniciativas favorables al establecimiento de Escuelas de Magisterio Rurales. Los continuos cambios en los planes de estudios de magisterio, reflejan la indefinición de la política educativa así como la pobreza de miras respecto a la educación pública. Este panorama de inestabilidad tampoco contribuía a consolidar una buena reputación de la profesión magisterial. La prioridad de los contenidos ideológicos frente a los pedagógicos, con la finalidad de potenciar los principios patrióticos, morales y religiosos para modelar las conciencias. Dados los intereses de controlar y amedrentar a la población se desplegó la pedagogía autoritaria. Con el objetivo de destruir y anular las innovaciones pretéritas se persiguieron aquellas iniciativas que no fueran afines a la dictadura.

La Falange Española Tradicionalista como partido político del régimen gozaba de una estructura organizativa para difundir el ideario político y adoctrinar a la población. Disponía de dos instituciones encargadas de formar a la juventud de uno y otro sexo en los postulados del régimen, como garantía de continuidad y de defensa frente a otros ideales. El Frente de Juventudes primero y la Organización Juvenil Española después se ocuparon de la instrucción de los jóvenes y la Sección Femenina de las jóvenes, acuñando los perfiles de hombre y de mujer. El discurso de la Organización Juvenil Española y de la Sección Femenina se fue adaptando a las exigencias políticas que el régimen iba demandando para la formación de las nuevas generaciones. La masculinidad asociada al perfil que regía el sistema patriarcal, de hombre autoritario, representante de la familia con

114 espacio de acción en la esfera de lo público, alejado de la vida privada... Desde la educación en la familia, en la escolaridad y socialización se reforzaba el rol masculino. 
La evolución política de la dictadura se corresponde con la evolución de las políticas educativas y de género. Todos los planes de estudio incorporaban contenidos sexistas y materias específicas en función de la dualidad de los roles sociales definidos en aquel entonces. Solo el Plan de 1971 unificó el currículum aunque la supresión de las materias no significó la igualdad de género. El ideal de masculinidad y feminidad con sesgos de género marcaban el diseño de los programas educativos. La educación marcadamente sexista se reforzó a través de los planes de estudio de magisterio con materias diferenciadas, toda vez que maestros y maestras se encargarían de reproducir los patrones culturales y de conducta en las escuelas de enseñanza primaria de toda la geografía española. Las materias diferenciadas en los estudios de magisterio marcaron patrones de conducta sexuados que debían reproducir en la escuela y modelar a las nuevas generaciones en base en ellos. Tanto la feminidad como la masculinidad se proyectaron a través de la educación. Las maestras eran modelos de mujer y a su vez los maestros representaban el modelo de hombre. Las imágenes que proyectaban en la infancia, servían de imagen y semejanza de los respectivos géneros a través de los que inculcaban sus patrones de conducta que convenía al orden vigente. Las maestras eran modelos de mujer, ejemplos a imitar, por ello debían tener un comportamiento intachable y una vida recatada. No solo por la influencia que ejercían en las niñas de la escuela sino en las jóvenes y mujeres del entorno donde desempeñaban su profesión. De igual modo los maestros ejercían influencia en la escuela y el entorno, aunque ejemplo de masculinidad y de fidelidad al régimen, no estaban sometidos a las restricciones morales que sufrían las maestras por el hecho de ser mujeres. La identidad de la mujer estaba definida por su papel en la familia y la subordinación al sistema patriarcal. Los cambios políticos y sociales protagonizados en la década de los setenta abrieron perspectivas, provocaron una adaptación de los discursos a los nuevos retos de las mujeres, encaminados a una mayor participación en la esfera pública. De forma paulatina se fueron modificando los comportamientos y flexibilizando la incorporación de las mujeres al mundo laboral. El programa sexista se mantuvo vigente hasta la Ley de 1970. A pesar de producirse cambios importantes en la mentalidad masculina y femenina, a finales del franquismo los modelos sexuados permanecían inalterados y la coeducación seguía ausente. El discurso político infiltrado en los objetivos 
formativos también marcó patrones androcéntricos en todos los ámbitos de la vida española, cuyo lastre aún no se ha superado. Volver la mirada atrás, casi ochenta años después del golpe militar, tras cuarenta años de dictadura y cuarenta años de democracia, nos revela el sinuoso camino recorrido en la formación inicial del magisterio. Una trayectoria teñida por los valores del Estado nacional católico, constreñida por el desinterés por el magisterio y, por ende, de la educación popular.

\section{Bibliografía}

Alares López, Gustavo. Políticas del pasado en la España franquista (19391964). Historia, nacionalismo y dictadura. Madrid: Marcial Pons, 2017.

Aranzadi, Estanislao de. Repertorio cronológico de legislación 1940. Pamplona: Imprenta Aranzadi, 1941.

Beas, Miguel. "Formación del magisterio y reformas educativas en España: 1960-1970”. Profesorado. Revista de curriculum y formación del profesorado, Vol. 14, No 1 (2010): 397-414.

Camprubí Bueno, Lino. Los ingenieros de Franco. Barcelona: Crítica, 2017.

Carreño, Miryam y Teresa Rabazas Romero. "Sobre el trabajo de ama de casa. Reflexiones a partir del análisis de manuales de Economía doméstica”. Revista Complutense de Educación, Vol. 21, No 1, (2010): 55-72.

Cenarro Lagunas, Angela. “Género y ciudadanía en el Franquismo”. Ayer, No 102 (2016): 13-21.

Cenarro Lagunas, Angela. "Miradas y debates sobre la violencia franquista". Ayer, No 91 (2013): 241-253.

Cruz Orozco, José Ignacio. Falange, Frente de Juventudes y el nuevo orden europeo. Discrepancias y coincidencias en la política de juventud durante el primer franquismo”. Revista de Educación, No 357 (2012): 515-535.

Dios Fernández, Eider de. "Domesticidad y familia: ambigüedad y contradicción en los modelos de feminidad. Ambigüedad y contradicción entre los modelos de feminidad en el franquismo". En Feminismo/s, $\mathrm{N}^{\circ} 23$ (2014): 23-46. 
Dios Fernández, Eider de. "Las que tienen que servir» y las servidas. La evolución del servicio doméstico en el franquismo y la construcción de la subjetividad femenina”. Revista Historia Autónoma, No 3 (2013): 97-111.

Fernández Jiménez, María Antonia. Pilar Primo de Rivera: el falangismo femenino. Madrid: Síntesis, 2008.

Franco, Rosario. ¿Eternas menores? Las mujeres en el franquismo. Madrid: Biblioteca Nueva, 2007.

González Pérez, Teresa. "Formar maestros y maestras para la patria nacional-católica. Los estudios de magisterio en la España franquista (1936-1975)"'. History of Education \& Children's Literature, XII/ 2 (2017): 69-91.

Lagos Arias, Nahir. "Memorias de una educación represiva”. Revista Murciana de Antropología, No 23 (2016): 203-224.

López Bausela, José Ramón. La contrarrevolución pedagógica en el franquismo de guerra. El proyecto político de Pedro Sainz Rodríguez. Madrid: Biblioteca Nueva / Ediciones de la Universidad de Cantabria, 2011.

López Bausela, José Ramón. Los programas escolares inéditos de 1938 en la España de Franco. El cerco pedagógico a la modernidad. Madrid: UNED/Universidad de Cantabria, 2012.

López Bausela, José Ramón. La escuela azul de Falange Española de las J.O.N.S.: Un proyecto fascista desmantelado por implosión. Santander: Dykinson/ Ediciones Universidad Cantabria, 2017.

Lomas, Carlos. "¿La escuela es un infierno? Violencia escolar y construcción cultural de la masculinidad”. Revista de Educación, No 342, (2007): 83-101.

Maíllo, Adolfo. Educación y revolución. Los fundamentos de una educación nacional. Madrid: Editora Nacional, 1943.

Mainer Baqué, Juan y Julio Mateos Montero. Saber, poder y servicio. Un pedagogo orgánico del Estado: Adolfo Maíllo. Valencia: Tirant lo Blanch, 2011.

Manrique, Juan Carlos López, Víctor Manuel, Luis Torrego, y Roberto. "Monjas, La labor formativa desarrollada por la Sección Femenina de la Falange en la preparación de sus mandos e instructoras durante 
el período franquista". Historia de la Educación. Revista Interuniversitaria, No 27 (2008): 347-365.

Manrique Arribas, Juan Carlos. "Incidencia del ideal de mujer durante el franquismo en el ámbito de la familia y la actividad física”. Feminismo/os, No 23 (2014): 47-68.

Manrique Arribas, Juan Carlos. "Actividad física y juventud en el franquismo (1937-1961)". Revista Internacional de Medicina y Ciencias de la Actividad Física y el Deporte, No 14/55 (2014): 427-449.

Martí Ferrándiz, José Joaquín. Poder político y educación. El control de la enseñanza (España, 1936-1975). Valencia: Universidad, 2002.

Maza Zorrilla, María Elena. "Las reglas del juego del nacionalcatolicismo". En La revolución educativa en la segunda república y la represión franquista. Editado por Ana Esteban y María Jesús Izquierdo. Valladolid: Ediciones de la Universidad de Valladolid, 2014, 137-146.

Molinero, Carme. "Mujer, franquismo, fascismo. La clausura forzada en un mundo pequeño". Historia Social, No 30 (1998): 97-117.

Montero, Feliciano y Joseba Louzao (eds.). Catolicismo y franquismo en la España de los años cincuenta. Autocríticas y convergencias Granada: Comares, 2016.

Morcillo, Aurora. "El género en lo imaginario. El "ideal católico femenino” y estereotipos sexuados bajo el franquismo”. En Represión, resistencias, memoria Las mujeres bajo la dictadura franquista. Mary Nash (ed.).Granada: Comares Historia, 2013, 71-90.

Muñoz Ruiz, María Carmen. "La construcción de las relaciones de género en el franquismo y sus conflictos. Los consultorios sentimentales". Arenal, No 10-2 (2003): 219-239.

Palma Valenzuela, Andrés. Avemarianos. Identidad y memoria. Granada: Escuelas Ave María, 2005.

Palma Valenzuela, Andrés. El Seminario de Maestros del Ave-María. Un compromiso por la renovación social y educativa. Granada: Universidad de Granada, 2008.

Palma Valenzuela, Andrés. "Maestros del pueblo para el pueblo. En: Revista de Antropología Experimental, No 10 (2010): 179-193.

Peinado, Matilde. "Las mujercitas" del franquismo: cómo enseñar y aprender un modelo de feminidad (1936-1960)"'. Estudios Feministas, No 24/1 (2016): 281-293. 
Peinado, Matilde y José Luis Anta Félez. Educar para el matrimonio en femenino: modelos y prácticas en la literatura de posguerra. Revista Athenea Digital, No 13/2 (2013): 35-46.

Peralta Ortiz, María Dolores. "Los proyectos sobre los estudios de magisterio en los comienzos del franquismo”. Bordón. Revista de pedagogía, No 52/1, (2000): 69-86.

Peralta Ortiz, María Dolores. La escuela primaria y el magisterio en los comienzos del franquismo. Madrid: Universidad Pontifica de Comillas, 2012.

Pozo Andrés, María del Mar del y Rabazas Romero, Teresa. "Políticas educativas y prácticas escolares: la aplicación de la ley de enseñanza primaria de 1945 en las aulas”. Bordón. Revista de pedagogía, Nº5/4, (2013): 119-133.

Rabazas Romero, Teresa. "Modelos de mujer sugeridos a las maestras en el franquismo”. Bordón. Revista de pedagogía, No 53/3, (2001): 423442.

Rabazas Romero, Teresa. "La educación física del Magisterio femenino en el Franquismo”. Revista Complutense de Educación, No 11/2, (2000): 167-198.

Rabazas Romero, Teresa. "El currículo femenino de las maestras a través de los libros de texto (1938-1970)". En La maestra en el proceso de cambio social de transición democrática: Espacios histórico-generacionales Sonsoles San Román Gago. Madrid: Instituto de la Mujer/ Ministerio de Trabajo y Asuntos Sociales, 2002, 127-207.

Saz Campos, Ismael. "Franco, ¿Caudillo fascista? Sobre las sucesivas y contradictorias concepciones falangistas del caudillaje franquista". En Historia y política: Ideas, procesos y movimientos sociales, $\mathrm{N}^{\mathrm{o}}$ 27, (2012): 27-50.

Riquer i Permanyer, Borja. La dictadura de Franco. Madrid: Marcial Pons, 2010.

Viñao Frago, Antonio. "La educación en el franquismo (1936-1975). Educar em Revista, No 51 (2014): 19-35.

Zaballos Crespo, Josefa. "Una mirada en la historia del CES Don Bosco de Madrid". Educación y futuro: Revista de investigación aplicada y experiencias educativas, $\mathrm{N}^{\circ} 18$ (2008): 45-69. 
Zaballos Crespo, Josefa. "Origen y evolución histórica de la escuela universitaria "Don Bosco"”. (Tesis doctoral dirigida por María del Carmen Labrador Herráiz. Universidad Complutense de Madrid, 2003).

\section{Fuentes documentales:}

Archivo de la Fundación Universitaria Española (AFUE).

Fondo de Pedro de Sainz Rodríguez.

Vocación profesional. Base XVIII.

Boletín Oficial del Estado (BOE) no 172, de 19 de diciembre de 1938, 3036.

Colección Legislativa del Ministerio de Educación Nacional, 1940.

Circular del Director General de Enseñanza Primaria dirigida a los directores de Escuelas de Magisterio del 12 de febrero de 1940.

Documentos de la Sección Femenina de la FET y de las JONS.

Legislación:

Anteproyecto de Ley de Bases de la Enseñanza Primaria y Normal.

Reglamento de Escuelas del Magisterio, Decreto de 7 de julio de 1950.

Ley sobre Educación Primaria de 17 de julio de 1945.

Planes de Estudio de Magisterio (Planes de 1942, 1945, 1950, 1965 y 1971)

Órdenes de 7 de noviembre y 11 de diciembre de 1939.

Orden de 28 de diciembre de 1939.

Orden de 14 de julio de 1939.

Revistas:

Escuela Española, no 25 (1941), no 65 (1941), no 71 (1942), no 48 (1942).

Revista Nacional de Educación, no 4, Madrid, MEN, (1941)

El Magisterio Español, no 6741 (1940), no 6658 (1939), no 6696 (1940): 683.

Para citar este artículo: González Pérez, Teresa. "El discurso educati-

120 vo del nacionalcatolicismo y la formación del magisterio español", Vol. XIII No. 33 (Julio-Diciembre 2018): 81-118. http:/ / dx.doi.org/10.15648/ hc.33.2018.5 